\title{
Non-consumptive predator effects constrain herbivorous fish distribution and abundance at upper mesophotic depths (30-50 m).
}

\author{
Corinne Kane ${ }^{1}$, Heather Spalding ${ }^{2}$, and Brian Tissot $^{3}$ \\ ${ }^{1}$ Washington State University \\ ${ }^{2}$ College of Charleston \\ ${ }^{3}$ Humboldt State University
}

October 1, 2020

\begin{abstract}
Herbivorous fishes play integral roles in preventing macroalgae from displacing corals, yet appear to decline with depth despite the presence of coral-dominated habitats to $>80 \mathrm{~m}$. We investigated the relationship between herbivorous fish and a suite of bottom-up and top-down parameters (algal turf, macroalgal and coral cover, nutritional quality and palatability, temperature, light, and predator density) along a depth gradient from 3-50 m. Fishes were not food-limited as upper mesophotic algae had similar nutritional content, assemblages, and appeared highly palatable from algal choice experiments. In-situ temperature recordings suggest temperature was not a limiting factor. Multivariate redundancy analyses reveal the combination of increased habitat patchiness and reduced light levels best explain distributions with depth. These results suggest reductions in herbivorous fish populations across shallow to upper mesophotic depths are likely the result of non-consumptive predator effects and behavioral choices rather than abiotic constraints or resource limitation.
\end{abstract}

\section{Introduction}

Herbivorous fishes are an integral component of coral reef ecosystems and play crucial roles in maintaining coral-dominated states (Fox and Bellwood 2007; Adam et al. 2015; Steneck et al. 2017). Limitations to spatial distribution of herbivorous fishes in shallow waters $(<30 \mathrm{~m})$ are largely attributed to bottom-up processes; temperature has been shown to limit herbivorous fish distributions across latitudinal gradients within shallow tropical systems (Floeter et al. 2005). Differences in temperature exceeding $8^{\circ} \mathrm{C}$ can inhibit metabolic efficiency in herbivorous fishes, thus constraining their distributions regardless of algal resources (Floeter et al. 2005; Smith 2008). Herbivorous fishes have been hypothesized to be inhibited from mesophotic habitats as these habitats are often characterized by cooler, more nutrient rich water (Hinderstein et al. 2010).

At finer spatial scales, herbivorous fish distribution is largely attributed to bottom-up effects resulting from resource availability (Russ 2003; Cvitanovic and Hoey 2010). Recent studies reveal herbivorous fishes cue specifically to algal quality and productivity rather than simply algal prevalence (Adam et al. 2015; Tootell and Steele 2016). It is purported that nutrient levels increase at MCE depths due to the influx of colder, more nutrient rich waters (Kahng et al. 2010). Conversely, reductions in light with depth are inferred to reduce algal productivity and inhibit visual acuity (Nemeth and Appeldoorn 2009; Brokovich et al. 2010a, 2010b). It is currently unclear how the interplay between nutrient and light levels affect algal productivity. Additionally, studies have shown mesophotic algae to be more highly chemically defended and thus less palatable to herbivorous fishes (Hay 1981; Gutow et al. 2014).

Resource availability and productivity may also interact with predation risk to influence the spatial distribution of herbivorous fishes. While algal resources influence centers of distributions, predation may influence 
the margins of distributions at smaller spatial scales. Top-down effects influencing distributions of prey organisms have been thoroughly demonstrated in rocky intertidal systems (Paine 1980; Menge 1995) yet has received less attention in structuring subtidal systems. The role of predation (direct or indirect) in structuring herbivorous fish communities appears variable. Davis et al. (2017a, 2017b) has shown predation influences behavior but not space use in parrotfishes, while others contend predation risk shapes behavior and distribution (Catano et al. 2016, 2017; Gil et al. 2017). Recent work by Papastamatiou et al. (2015) reveal the first evidence of sharks and trevally movement and foraging between shallow and mesophotic depths, indicating that mobile predators are utilizing mesophotic reefs as foraging grounds.

Based on our understanding of shallow-water mechanisms controlling herbivorous fish abundance and possible limitations with depth, we conducted a suite of observational and experimental studies on the leeward coast of Hawai'i to evaluate potential bottom-up and top-down mechanisms affecting the depth distribution of herbivorous fishes. Specifically, we sought to test how herbivorous fish distributions between shallow $(<30$ $\mathrm{m})$ and upper mesophotic $(30-50 \mathrm{~m})$ depths were influenced by 1$)$ bottom-up effects resulting from thermal barriers, habitat, resource composition/nutritional value; and 2) predation effects resulting from direct and indirect predation pressures.

\section{Methods}

\section{Study sites}

Hawai'i Island has a steeply sloping bathymetry and extensive coral reefs that spread continuously from shore to depths of approximately $50 \mathrm{~m}$. Eleven sites were selected along West Hawai'i's coastline in areas where continuous coral-reef habitat occurs from shallow waters $(5-30 \mathrm{~m})$ to at least $50 \mathrm{~m}$ (Fig. 1). Only continuous reefs that spanned from 5-50+ $\mathrm{m}$ were selected to avoid potential barriers to movement resulting from large sand breaks between reef areas. Due to the steep slope of Hawai'ian reefs, the $50 \mathrm{~m}$ depths surveyed were often within 100-200 $\mathrm{m}$ of the shoreline, thus physical distance between the shallowest and deepest surveys were between 50 and $200 \mathrm{~m}$ from shore.

\section{Fish and benthic sampling design}

A stratified sampling design was used to explore changes in fish abundance and trophic structure with depth. Concordant depth and bathymetric relief among sites were sought to maintain consistency and reduce potential survey bias. Visual surveys of reef fish and benthic substrates were conducted on SCUBA at approximately 10-m depth intervals during June-August in 2013-2015. Due to variability of habitat below $30 \mathrm{~m}$, three sites were sampled to $50 \mathrm{~m}$, seven to $40 \mathrm{~m}$ and one to $30 \mathrm{~m}$. This resulted in an unequal survey design with 35 surveys at $3 \mathrm{~m}, 37$ surveys at $10 \mathrm{~m}, 38$ surveys at $20 \mathrm{~m}, 38$ surveys at $30 \mathrm{~m}, 34$ surveys at $40 \mathrm{~m}$, and 30 surveys at $50 \mathrm{~m}$ (for complete details see Kane and Tissot 2017). Visual fish surveys were conducted at each depth $(3-50 \mathrm{~m})$ using a $25 \mathrm{~m} \mathrm{x} 4 \mathrm{~m}$ belt transect. Belt length, width and level of replication per depth (minimum $\mathrm{n}=3$ ) were dictated by technical constraints resulting from the short bottom times allowed from using SCUBA at $50 \mathrm{~m}$ depths (Brokovich et al. 2008; Sandin et al. 2008). Within each fish belt transect, all fishes were identified to species (following Randall 2007) and tallied individually. Benthic survey data were collected at two of the replicate transects within each depth by photographing a $0.25-\mathrm{m}^{2}$ quadrat every meter ( $\mathrm{n}=25$ per transect) using an underwater camera equipped with a PVC photoquadrat framer and dual lighting system.

All fishes encountered in surveys were assigned trophic designations according to gut content analyses published on Hawaiian fish species in Hobson (1974) and Randall (2007), and corroborated with databases from National Oceanic and Atmospheric Administration's Pacific Islands Fisheries Science Center for Hawai'i.

Benthic photoquadrat samples were analyzed using CoralNet benthic image analysis (Beijbom et al. 2015). Fifty random points were placed within each photograph and the biota or substratum directly underneath each point was identified to the lowest taxonomic classification possible (see Kane and Tissot 2017). Taxonomic identifications were pooled to create descriptive habitat categories which included turf algae, macroalgae, sand, and live coral cover that are strongly correlated with reef-fish community composition at shallow 
depths (Friedlander and Parrish 1998; Hoey et al. 2013). Categories were summed by photoquadrat and averaged $(\mathrm{n}=25)$ to obtain one cover estimate per transect to correspond with fish transects.

\section{Temperature and light sampling}

Temperature $\left({ }^{\circ} \mathrm{C}\right.$ ) and irradiance (lumens $\left./ \mathrm{ft}^{2}\right)$ estimates were collected at each survey site and depth from 3-40 m (50 m depths not recorded as sensors malfunctioned due to exceeding max depth ratings). Four identical HOBO Pendant Temperature/Light data loggers (UA-002-64; Onset Computer Corporation) were affixed to an aluminum plate with each sensor spaced linearly at $10 \mathrm{~cm}$ intervals with a sampling interval of 1 measurement every 10 seconds upon submersion. The plate was positioned on top of the substrate with the face of the sensors facing directly upward for a minimum of 8 minutes per depth interval. Data loggers were then downloaded, and the last five minutes of each depth recording were extracted to ensure sufficient time to calibrate at each depth.

Temperature and irradiance levels were averaged by sensor and then among sensors at each depth within each site, resulting in one averaged estimate per depth. Differences in irradiance levels among depths were estimated by dividing the depth of interest by the shallowest depth recorded (near-surface; $3 \mathrm{~m}$ ) to obtain the percentage of light available at each depth relative to the near-surface $(3 \mathrm{~m})$ depth.

\section{Algal identification and Quality}

Initial estimates of algal composition and prevalence were compiled via photoquadrat analyses. As certain algal groups could not be easily identified via photographs (turfs, small algae), representative voucher samples were collected from one site to further classify algae not readily identifiable in photographs. Three representative rubble/rock matrices were collected from $10 \mathrm{~m}$ (shallow; $7.0 \times 5.5 \times 4.5 \mathrm{~cm}$ ) and $40 \mathrm{~m}$ (upper mesophotic; $7.5 \times 5.0 \times 4.5 \mathrm{~cm}$ ) depths via SCUBA on 4 August 2016 at Puako (Fig. 1). Each sample was individually frozen in a plastic bag after collection. Rocks were unthawed on 27 May 2017, photographed, and all visible algae were removed under a dissecting scope and identified to the lowest possible taxonomic level using a microscope and reference books (Abbott 1999, Abbott and Huisman 2004, Huisman et al. 2007). Algal nomenclature was updated using Algaebase (Guiry and Guiry 2017). Each specimen was processed according to Tsuda and Abbott (1985) and given a collection number (HS) from the herbarium of H. L. Spalding (HS452 - HS479).

$\mathrm{C}: \mathrm{N}$ ratios were extracted to test nutrient contents of turf algae between shallow and mesophotic depths. Thirty samples of representative turf algae were collected by hand at $10 \mathrm{~m}$ and $40 \mathrm{~m}$ depths at Puako (Fig. 1) in August 2016. Samples were placed in zip-lock bags and transported in sea water to the lab, rinsed, wet-weighted and then dried at $60^{\circ} \mathrm{C}$ for 48 hours. Samples were then ground with mortar and pestle until a fine powder was produced. $\mathrm{C}$ and $\mathrm{N}$ contents were determined using a Flash $2000 \mathrm{NC}$ soil analyzer (CE Elantech) against an aspartic acid, $\mathrm{C}_{3} \mathrm{H}_{7} \mathrm{NO}_{4}$ organic analytical standard (OAS: Elemental $\mathrm{C}$ values 36.09, Elemental $\mathrm{N}$ values 10.52).

An in-situ algal choice experiment was conducted to assess the palatability of turf algae from mesophotic depths. Three sand/rubble patches located adjacent to large coral reef tracts were selected at $10 \mathrm{~m}$ depth at Old Airport (Fig. 1). In each of these patches, 10 pairs of experimental plots were set up ( $n=30$ total). Each plot consisted of a large cinder block with an attached $60 \mathrm{~cm}$ PVC pipe (1 in diameter). A GoPro Hero 3 (white edition) camera was affixed to the top of the PVC pipe to record fish behaviors without distractions by divers. In front of each camera, a paired design consisted of one control plot $(30 \mathrm{~cm} \mathrm{x} 30 \mathrm{~cm}$ area filled with turf algae-covered rubble collected from the adjacent reef area at $10 \mathrm{~m}$ depth) and one experimental plot $(30 \mathrm{~cm} \times 30 \mathrm{~cm}$ area with turf algae-covered rubble collected from $40 \mathrm{~m}$ depth and transported up to the experimental site) set $1 \mathrm{~m}$ apart from each other. After setup, cameras were turned on and recorded for approximately 30 minutes. To control for discovery time, we began analysis of each treatment video at 5 minutes and analyzed fish activity for 20 minutes. Within the 20-minute time frame, we identified every fish visible to species and recorded total visitation time by each fish, the amount of time each fish investigated and/or grazed on algae, and number of bites taken during each foraging bout. 


\section{Behavioral observations}

We conducted observations of herbivorous fishes to examine behavioral patterns in both shallow $(<10 \mathrm{~m})$ and upper mesophotic $(30-50 \mathrm{~m})$ coral reef environments. We selected Zebrasoma flavescens (Acanthuridae) and Scarus psittacus (Scarinae) as representative species because they were the most commonly observed fish in both shallow and upper mesophotic depths during transect surveys. Focal observations of adult $Z$. flavescens and S. psittacus were conducted at two sites, Puako (northern region) and Old Airport (central region)(Fig. 1). Within each site, we selected 20 adult fish at each depth treatment; shallow observations included fishes found at 3-10 m depths, while upper mesophotic observations included fishes from 30-50 m depths. Focal observations were conducted by attaching a GoPro camera to a $2 \mathrm{~m}$ PVC pipe; SCUBA divers selected one fish and carefully filmed them for a period of 5 minutes from a distance of at least $5 \mathrm{~m}$. If the focal fish was startled by the diver or went out of view of the diver at any time during the 5-minute session, filming was aborted and another fish was selected. Extensive communication between divers at each depth and detailed notes collected on visual fish identities during video analysis were used to ensure the same fish were not enumerated multiple times.

Behaviors were binned into six categories; foraging (fish actively grazing on substrate), swimming (fish actively moving), aggressor (focal fish actively chasing another fish), victim (focal fish actively being chased by another fish), courtship (spawning behaviors and territorial patrolling; swimming $>2 \mathrm{~m}$ above substrate in a repetitive pattern), or other (any additional behaviors not previously outlined, such as time spent at cleaning stations).

\section{Data analysis}

Sites were grouped into three geographic regions (North, Central, South Kohala-Kona coast) to ensure adequate sampling effort for analyses (Fig. 1). Fish abundance and behaviors were calculated using two factor generalized linear models (GLM; abundance analyses with Poisson distribution, focal observations with Gaussian distributions; JMP 12.1.0, SAS Institute Inc.). Analysis of environmental predictors for herbivorous fish distributions were conducted using a multivariate distance-based linear model with Best selection approach (distLM; Primer v. 6.1.13, Primer-E+). Prior to analysis, all variables were tested and transformed as appropriate for skewness. Multi-collinearity tests revealed no two variables showed correlations greater than 0.65 so all variables were retained for analysis.

\section{Results}

\section{Herbivore distributions}

A total of 5,253 fish from 33 herbivorous species were counted during transect surveys (Appendix S1: Table S1). The herbivore assemblage was dominated largely by acanthurids (17 species), which encompassed $80 \%$ of all fishes encountered. Labrid fishes (subfamily Scarinae) and pomacanthid fishes were the second-most common families (labrid: 5 spp., pomacanthid: 2 spp.) and each comprised approximately $7 \%$ of fish surveyed. Acanthurid fishes differed significantly across both depth and regions sampled (GLM: depth $\chi^{2}{ }_{5,212}=1792.28$, $\mathrm{P}$ [?] 0.001; region $\chi_{2,212}^{2}=35.42, \mathrm{P}$ [?] 0.001; depth $\mathrm{x}$ region $\chi^{2}{ }_{10,212}=262.11$, $\mathrm{P}$ [?] 0.001; Fig. 2a). Scarinae differed significantly across both depths and regions sampled (GLM: $\operatorname{depth} \chi^{2}{ }_{5,212}=111.67, \mathrm{P}$ [?] 0.001; region $\chi^{2}{ }_{2,212}=16.31, \mathrm{P}=0.003$; depth $\mathrm{x}$ region $\chi^{2}{ }_{10,212}=104.4, \mathrm{P}$ [?] 0.001; Fig. 2b). Pomacanthid species exhibited significant patterns across depth and depth $\mathrm{x}$ region interactions, but no significant differences among regions sampled (GLM: depth $\chi^{2}{ }_{5,212}=127.95$, P [?] 0.001; region $\chi_{2,212}^{2}=$ 0.0004, P $=0.99$; depth $\mathrm{x}$ region $\chi_{10,212}^{2}=54.83$, P [?] 0.001; Fig. 2c). The remaining herbivorous families were pooled due to low overall abundances, and were also found to decrease significantly with depth, but did not differ significantly between regions (GLM: $\operatorname{depth} \chi_{5,212}^{2}=247.7$, P [?] 0.001; region $\chi_{2,212}^{2}=5.89, \mathrm{P}$ $=0.052$; depth $\mathrm{x}$ region $\chi^{2}{ }_{10,212}=38.64, \mathrm{P}$ [?] 0.001; Fig. 2d). While herbivorous fishes in all regions declined with depth, a significant interaction between region and depth occurred as a result of higher abundances at the northern sites.

DistLM analysis indicated significant relationships between herbivorous fish community structure and 5 of 
7 variables tested (macroalgae and temperature not statistically significant; Appendix S1: Table S2). The model that best explains herbivorous fish distributions (lowest AIC values) incorporates a combination of light, coral cover and sand cover variables and accounts for approximately $14 \%$ of the total variation in herbivorous fish communities (Table 1).

\section{Predator distributions}

Piscivorous fishes were mostly comprised of site-attached species (17 spp.) while mobile piscivores were rare and comprised of few species (6 spp.; Fig. 3a). Piscivores differed significantly between depths and between depth $\mathrm{x}$ region, but were not significantly different between regions (Fig. 3b; GLM: $\operatorname{depth} \chi^{2}{ }_{5,212}=18.96, \mathrm{P}$ $=0.002$; region $\chi_{2,212}^{2}=1.81, \mathrm{P}=0.41$; depth $\mathrm{x}$ region $\chi^{2}{ }_{10,212}=37.93, \mathrm{P}$ [?] 0.001).

\section{Temperature and Light sampling}

Water temperatures averaged $28.6^{\circ} \mathrm{C}$ at $3 \mathrm{~m}$ to $26.6^{\circ} \mathrm{C}$ at $40 \mathrm{~m}$. Temperature was highly variable between sites at $3 \mathrm{~m}$ depths, but relatively stable at 10-40 $\mathrm{m}$ depths. Light levels followed similar patterns as temperature with much more variability in irradiance at $3 \mathrm{~m}$ depths and more stable irradiance at deeper depths. Irradiance decreased sharply with depth; $10 \mathrm{~m}$ depths averaged $39.5 \%$ of surface light available at $3 \mathrm{~m}, 20 \mathrm{~m}$ depths $22 \%, 30 \mathrm{~m}$ depths $12.8 \%$, and $40 \mathrm{~m}$ depths averaged $7.8 \%$ of light levels at $3 \mathrm{~m}$.

\section{Algal Identification and Quality}

The shallow and upper mesophotic algal communities had a low abundance of macroalgae, with turf algae and brown dictyotalean blades most visually apparent (Appendix S1: Table S3). Within voucher samples, most macroalgae were diminutive $(<1 \mathrm{~cm}$ long) and sterile, making identifications to the species level difficult without molecular techniques. Shallow algal communities had the highest cover of visually apparent macroalgae and species diversity (35 species/genera), while the upper mesophotic communities were more depauperate with lower diversity (21 species/genera; ESM 3). Overlap in species composition was high, with two-thirds of the upper mesophotic species also found in shallow samples, including three abundant brown macroalgae (Dictyota sp.,Padina sp., and Stypopodium flabelliforme ; ESM 3). These species of brown algae belong to the Dictyotaceae, a family known to have antiherbivory compounds and inducible antiherbivory defenses (Hay 1992; Macaya and Thiel 2008). All of the upper mesophotic genera have also been described from shallow water (Abbott 1999; Abbott and Huisman 2004), although species-level identifications would be necessary to evaluate possible overlap.

Carbon and nitrogen inputs of turf algae collected from $10 \mathrm{~m}$ and $40 \mathrm{~m}$ depths revealed no significant differences between depths for carbon $\left(\mathrm{t}_{1,57}=0.15, \mathrm{P}=0.88\right)$, nitrogen $\left(\mathrm{t}_{1,57}=0.65, \mathrm{P}=0.52\right)$, or $\mathrm{C}: \mathrm{N}$ ratios $\left(\mathrm{t}_{1,57}=0.24, \mathrm{P}=0.81\right)$. Mean levels of $\% \mathrm{C}$ were $13.47 \%(+/-0.28 \mathrm{SE})$ at $10 \mathrm{~m}$ vs. $13.53 \%(+/-0.28 \mathrm{SE})$ at $40 \mathrm{~m}$. Nitrogen composition averaged $0.67 \%(+/-0.03 \mathrm{SE})$ at $10 \mathrm{~m}$ and $0.7 \%(+/-0.03 \mathrm{SE})$ at $40 \mathrm{~m}$. Mean C:N ratios at $10 \mathrm{~m}$ were $21.19(+/-1.07 \mathrm{SE})$ at $10 \mathrm{~m}$ and $20.83(+/-1.05 \mathrm{SE})$ at $40 \mathrm{~m}$.

During the algal choice experiment, both grazing time $\left(\chi^{2}{ }_{1,58}=11393.99, \mathrm{P}\right.$ [?] 0.001) and grazing intensity $\left(\chi_{1,58}^{2}=81.14\right.$, P [?] 0.001) were significantly greater on algae collected from $40 \mathrm{~m}$ depths. Grazing was dominated largely by small-bodied surgeonfish (Zebrasoma flavescens, Acanthurus nigrofuscus, Ctenochaetus strigosus), which accounted for $87 \%$ of the grazing time in shallow treatments, and $65 \%$ of the grazing time in upper mesophotic treatments. Large-bodied surgeonfish (Naso lituratus, Acanthurus olivaceous, Naso unicornis ) accounted for $5 \%$ of shallow grazing time and $15 \%$ of upper mesophotic grazing time, while parrotfish (Calotomus carolinus, Calotomus zonarchus, Chlorurus spilosoma, Scarus psittacus ) accounted for $7 \%$ of shallow grazing time and $13 \%$ of upper mesophotic grazing time.

\section{Behavioral observations}

Zebrasoma flavescens exhibited differences in foraging (GLM: depth $\mathrm{t}_{1,40}=0.49, \mathrm{P}=0.62$; site $\mathrm{t}_{1,40}=2.64$, $\mathrm{P}=0.009$; depth $\mathrm{x}$ site $\mathrm{t}_{1,40}=1.56, \mathrm{P}=0.12$ ), swimming (GLM: depth $\mathrm{t}_{1,40}=0.76, \mathrm{P}=0.45$; site $\mathrm{t}_{1,40}=$ $2.32, \mathrm{P}=0.02$; depth $\mathrm{x}$ site $\left.\mathrm{t}_{1,40}=1.85, \mathrm{P}=0.06\right)$ and aggressive behaviors (GLM: depth $\mathrm{t}_{1,40}=1.77, \mathrm{P}$ $=0.08 ;$ site $t_{1,40}=2.24, \mathrm{P}=0.03 ;$ depth 
$\mathrm{x}$ site $\mathrm{t}_{1,40}=1.3, \mathrm{P}=0.2$ ) between sites but not between depths (Fig. 4a). Differences were observed among both site and depth in submissive behaviors (GLM: depth $t_{1,40}=2.8, \mathrm{P}=0.006$; site $\mathrm{t}_{1,40}=2.21, \mathrm{P}=0.03$; depth $\mathrm{x}$ site $\mathrm{t}_{1,40}=1.91, \mathrm{P}=0.06$ ) with more fishes being chased in shallow waters than upper mesophotic waters. No significant differences were found among either sites or depths for courtship behaviors, as they were rarely observed (GLM: depth $\mathrm{t}_{1,40}=0.58, \mathrm{P}=0.57$; site $\mathrm{t}_{1,40}=0.1, \mathrm{P}=0.92$; depth $\mathrm{x}$ site $\mathrm{t}_{1,40}=0.75$, $\mathrm{P}=0.45)$.

Scarus psitticaus could not be found at upper mesophotic depths at the Old Airport site, precluding analyses comparing upper mesophotic/shallow behavior at this site. The resulting analyses were performed from observations at the Puako site only. S. psittacusexhibited differences between depths (Fig. 4b) in foraging (GLM: $\left.\mathrm{t}_{1,40}=3.64, \mathrm{P}=0.0008\right)$, swimming $\left(\mathrm{GLM}: \mathrm{t}_{1,40}=8.78, \mathrm{P}<0.0001\right)$ and courtship behaviors (GLM: $\left.\mathrm{t}_{1,40}=12.05, \mathrm{P}<0.0001\right)$. No significant differences were found between depths for aggressor, victim, or other behaviors, as they were uncommonly observed (GLM: aggressor $\mathrm{t}_{1,40}=0.025, \mathrm{P}=0.80$; victim $\mathrm{t}_{1,40}=$ $0.16, \mathrm{P}=0.87$; other $\mathrm{t}_{1,40}=1.03, \mathrm{P}=0.32$ ).

\section{Discussion}

Findings suggest that the lower limits of herbivorous fish distribution result from top-down, non-consumptive predation effects rather than resource limitation or metabolic constraints. Terrestrial research has highlighted the importance of non-consumptive predator effects, whereby prey are forced to modify foraging ranges to reduce predation risk (Peckarsky et al. 2008; Preisser et al. 2009). The "landscape of fear" model suggests prey alter their foraging behaviors in response to spatial and temporal heterogeneity in predation risk, and this model has recently been corroborated in marine ecosystems (Matassa and Trussell 2011; Catano et al. 2016; Davis et al. 2017a). While predator abundance was low among all depths surveyed, the lowlight environment at upper mesophotic depths likely inhibits visual acuity of herbivorous fishes more than piscivores, whose eyes are more well-adapted to low-light conditions (McFarland 1991). Our models of herbivore distribution indicate the combination of more patchily distributed habitat (increased sand cover and lower coral cover at upper mesophotic depths) as well as reduced light levels best explain the reduction in herbivorous fishes at upper mesophotic depths, supporting landscape of fear models. Studies of predators on mesophotic reefs are limited, but initial studies by Papastamatiou et al. (2015) in the Northwestern Hawaiian Islands reveal apex predators undergo regular diel movements between shallow and mesophotic depths and obtain approximately $35 \%$ of their diet from mesophotic reefs. The observed movement patterns of predators, in conjunction with decreased visual acuity from low light levels and reduced sheltering space likely enhance predation threat in herbivorous fishes at upper mesophotic depths (Brokovich et al. 2010b; Catano et al. 2016, 2017).

This theory is further supported when comparing the behavioral characteristics of the smaller bodied $Z$. flavescens to the larger bodied S. psittacus . During this study, Z. flavescensbehavioral characteristics were similar between depths, spending most of their time in upper mesophotic depths either foraging or swimming. Conversely, the larger bodied S. psittacus were only found in sufficient quantities for our behavioral study at one site (indicating more scarcity at depth) and their behaviors shifted from predominantly swimming at shallow depths to almost exclusively engaging in courtship behavior at upper mesophotic depths; indicating the main presence at depth is for spawning. In contrast with most terrestrial studies, vulnerability to predation in reef fishes has been positively correlated with body size, suggesting smaller bodied fishes are less wary in response to predators (Sinclair et al. 2003; Burkepile et al. 2013; Catano et al. 2016). Our work supports this observation, with smaller-bodied herbivores more commonly observed at upper mesophotic depths and larger-bodied herbivores rarely observed.

Light levels have been widely documented to generate strong bottom-up effects in both terrestrial and aquatic environments (Wootton and Power 1993; Stoepler and Lill 2013; Bennie et al. 2015). Conversely, we found that light levels likely facilitate top-down regulation of herbivorous fishes at upper mesophotic depths. Unlike studies in other systems, we found that decreased light levels did not constrain the quantity or quality of algal resources at upper mesophotic depths. Nitrogen composition was virtually identical between $10 \mathrm{~m}$ and $40 \mathrm{~m}$ turf algal samples. C:N ratios between shallow and upper mesophotic depths were also nearly identical, 
indicating the nutritional value of turf algae is not reduced at upper mesophotic depths. Instead, reductions in light levels at upper mesophotic depths likely affect the visual acuity of shallow reef fish species, thereby enhancing perceived predation risk (Brokovich et al. 2010b).

We were subsequently interested in parsing out changes in algal quality between shallow and mesophotic depths. While upper mesophotic algae appear to be just as nutritious as shallow algae, it is possible that upper mesophotic algae contain antiherbivory compounds and inducible antiherbivory defenses (Hay 1992, Macaya and Thiel 2008). We identified three abundant brown macroalgae in deep collections (Dictyotasp., Padina sp., and Stypopodium flabelliforme ) that belong to the Dictyotaceae, a family known to have antiherbivory compounds. Previous work in the Caribbean has shown reduced herbivory below $30 \mathrm{~m}$ was largely a result of increased chemical defenses in algal communities (Hay 1981, 1997; Slattery and Lesser 2014). Choice experiments reveal that unlike Caribbean reefs, shallow mesophotic algal communities in Hawai'i appear to be highly palatable. When algal communities from $40 \mathrm{~m}$ were transplanted to $10 \mathrm{~m}$ depth, fish spent significantly more time grazing and grazed more intensely on upper mesophotic algal communities than control $(10 \mathrm{~m})$ algal communities. We commonly observed upper mesophotic turf algal patches with turfs in excess of $3 \mathrm{~cm}$ length, indicating that turf algae at these depths are not commonly or heavily grazed. Yet, evidence of feeding at upper mesophotic depths and preferential feeding on upper mesophotic algae when transplanted to shallow depths do not translate to high grazer abundance or high grazing pressure at upper mesophotic depths, further supporting non-consumptive predation risk as the most probable mechanism limiting herbivore distribution with depth.

We still have much to learn regarding algal-herbivore interactions at mesophotic depths and the interplay between mesophotic and shallow reefs. The trends described in this study pertain to the upper mesophotic region of Hawai'i (30-50 m), yet mesophotic reefs in Hawai'i and around the world extend to depths of 100 $\mathrm{m}$ or greater (Kahng and Maragos 2006; Loya et al. 2016). It is unclear whether deeper mesophotic reefs undergo similar herbivore constraints as the upper mesophotic constraints described herein, or the lower temperatures (Pyle et al. 2019) and differing algal species composition (Spalding et al. 2019) of mid to lower mesophotic reefs may act in concert with the indirect effects of predation to further constrain herbivorous fish distributions. Additionally, the vast majority of predictive models for coral-algal-herbivore interactions do not include the role depth may play in limiting herbivore abundance (Mumby and Hastings 2007; Brokovich et al. 2010a; Adam et al. 2015). Hence, future attempts to address herbivore effects on coral reef resilience would benefit by further investigating mesophotic reefs addressing the lower extent of herbivorous fish depth ranges. These findings highlight opportunities for exploring alternative mechanisms influencing coral reef resilience, and the overall need to continue and expand mesophotic coral reef studies.

\section{Acknowledgments}

This research was generously supported by NOAA's Coral Reef Conservation Program (Grant \# NA13NOS4820026 and NA15NOS4820075), Waitt Foundation Rapid Ocean Conservation Grant, NOAA Nancy Foster Scholarship, NSF GK-12 Graduate Fellowship, and WSU Vancouver. We thank Dr. Bill Walsh and the Hawaii Division of Aquatic Resources for their support and guidance for the duration of this project. We graciously thank S. Annandale, G. Bernatchez, K.W. Bryan, K. Carlson, J. Coney, K. Conklin, A. Faucci, K. Flanagan, K. Gaab, L. Kramer, K. Lopes, T. Phelps, H. Shauer, D. Smith, J. Stewart, T. Terazono, A. Tissot, T. Wester and Kona Diving Company for their field and logistical support. We also thank Steve Henderson, Mark Hixon, Randall Kosaki, Cheryl Shultz and additional anonymous reviewers who provided insightful comments for this manuscript.

\section{Literature Cited}

Adam TC, Burkepile DE, Ruttenberg BI, Paddack MJ (2015) Herbivory and the resilience of Caribbean coral reefs : knowledge gaps and implications for management. Mar. Ecol. Prog. Ser. 520:1-20

Bennie J, Davies TW, Cruse D, Inger R, Gaston KJ (2015) Cascading effects of artificial light at night: resource-mediated control of herbivores in a grassland ecosystem. Philos. Trans. R. Soc. Lond. B. Biol. Sci. 370:20140131 
Brokovich E, Ayalon I, Einbinder S, Segev N, Shaked Y, Genin A, Kark S, Kiflawi M (2010a) Grazing pressure on coral reefs decreases across a wide depth gradient in the Gulf of Aqaba, Red Sea. Mar. Ecol. Prog. Ser. 399:69-80

Brokovich E, Ben-Ari T, Kark S, Kiflawi M, Dishon G, Iluz D, Shashar N (2010b) Functional changes of the visual system of the damselfish Dascyllus marginatus along its bathymetric range. Physiol. Behav. 101:413-21

Burkepile DE, Burns CE, Tambling CJ, Amendola E, Buis GM, Govender N, Nelson V, Thompson DI, Zinn AD, Smith MD (2013) Habitat selection by large herbivores in a southern African savanna: the relative roles of bottom-up and top-down forces. Ecosphere 4:art139

Catano LB, Barton MB, Boswell KM, Burkepile DE (2017) Predator identity and time of day interact to shape the risk-reward trade-off for herbivorous coral reef fishes. Oecologia 183:763-773

Catano LB, Rojas MC, Malossi RJ, Peters JR, Heithaus MR, Fourqurean JW, Burkepile DE (2016) Reefscapes of fear: Predation risk and reef hetero-geneity interact to shape herbivore foraging behaviour. J. Anim. Ecol. 85:146-156

Cvitanovic C, Hoey AS (2010) Benthic community composition influences within-habitat variation in macroalgal browsing on the Great Barrier Reef. Mar. Freshw. Res. 61:999-1005

Davis K, Carlson PM, Bradley D, Warner RR, Caselle JE (2017a) Predation risk influences feeding rates but competition structures space use for a common Pacific parrotfish. Oecologia 1-11

Davis K, Carlson PM, Lowe CG, Warner RR, Caselle JE (2017b) Parrotfish movement patterns vary with spatiotemporal scale. Mar. Ecol. Prog. Ser. 577:149-164

Floeter S, Behrens M, Ferreira C (2005) Geographical gradients of marine herbivorous fishes: patterns and processes. Mar. Biol. 1-19

Fox R, Bellwood D (2007) Quantifying herbivory across a coral reef depth gradient. Mar. Ecol. Prog. Ser. 339:49-59

Friedlander AM, Parrish JD (1998) Habitat characteristics affecting fish assemblages on a Hawaiian coral reef. J. Exp. Mar. Bio. Ecol. 224:1-30

Gil MA, Zill J, Ponciano JM (2017) Context-dependent landscape of fear: Algal density elicits risky herbivory in a coral reef. Ecology 98:534-544

Gutow L, Rahman MM, Bartl K, Saborowski R, Bartsch I, Wiencke C (2014) Ocean acidification affects growth but not nutritional quality of the seaweed Fucus vesiculosus (Phaeophyceae, Fucales). J. Exp. Mar. Bio. Ecol. 453:84-90

Hay ME (1992) The chemical ecology of plant-herbivore interactions in marine versus terrestrial communities. Herbivores : Their Interactions with Secondary Plant Metabolites. Academic Press, pp 371-413

Hay ME (1981) Herbivory, Algal distribution, and the maintenance of between-habitat diversity on a tropical fringing reef. Am. Nat. 118:520-540

Hay ME (1997) The ecology and evolution of seaweed-herbivore interactions on coral reefs. Coral Reefs 16:S67-S76

Hinderstein LM, Marr JC a., Martinez F a., Dowgiallo MJ, Puglise K a., Pyle RL, Zawada DG, Appeldoorn R (2010) Theme section on "Mesophotic Coral Ecosystems: Characterization, Ecology, and Management." Coral Reefs 29:247-251

Hoey AS, Brandl SJ, Bellwood DR (2013) Diet and cross-shelf distribution of rabbitfishes (f. Siganidae) on the northern Great Barrier Reef: Implications for ecosystem function. Coral Reefs 32:973-984 
Kahng SE, Garcia-Sais JR, Spalding HL, Brokovich E, Wagner D, Weil E, Hinderstein L, Toonen RJ (2010) Community ecology of mesophotic coral reef ecosystems. Coral Reefs 29:255-275

Kahng SE, Maragos JE (2006) The deepest, zooxanthellate scleractinian corals in the world? Coral Reefs $25: 254-254$

Loya Y, Eyal G, Treibitz T, Lesser MP, Appeldoorn R (2016) Theme section on mesophotic coral ecosystems: advances in knowledge and future perspectives. Coral Reefs 35:1-9

Macaya EC, Thiel M (2008) In situ tests on inducible defenses in Dictyota kunthii and Macrocystis integrifolia (Phaeophyceae) from the Chilean coast. Artic. J. Exp. Mar. Biol. Ecol.

Matassa CM, Trussell GC (2011) Landscape of fear influences the relative importance of consumptive and nonconsumptive predator effects. Ecology 92:2258-2266

Menge B (1995) Indirect effects in marine rocky intertidal interaction webs: patterns and importance. Ecol. Monogr. 65:21-74

Mumby PJ, Hastings A (2007) The impact of ecosystem connectivity on coral reef resilience. J. Appl. Ecol. $45: 854-862$

Nemeth M, Appeldoorn R (2009) The distribution of herbivorous coral reef fishes within fore-reef habitats: the role of depth, light and rugosity. Caribb J Sci 45:247-253

Paine RT (1980) Food Webs: Linkage, Interaction Strength and Community Infrastructure. J. Anim. Ecol. 49:666-685

Papastamatiou YP, Meyer CG, Kosaki RK, Wallsgrove NJ, Popp BN (2015) Movements and foraging of predators associated with mesophotic coral reefs and their potential for linking ecological habitats. 521:155170

Peckarsky B, Abrams P, Bolnick D, Dill L, Grabowski J, Luttbeg B, Orrock J, Peacor S, Preisser E, Schmitz O, Trussell G (2008) Revisiting the Classics : Considering Nonconsumptive Effects in Textbook Examples of Predator - Prey Interactions. Ecology 89:2416-2425

Preisser EL, Bolnick DI, Grabowski JH (2009) Resource dynamics influence the strength of non-consumptive predator effects on prey. Ecol. Lett. 12:315-323

Pyle RL, Kosaki RK, Pinheiro HT, Rocha LA, Robert K, Copus JM (2019) Fishes: Biodiversity.

Russ GR (2003) Grazer biomass correlates more strongly with production than with biomass of algal turfs on a coral reef. Coral Reefs 22:63-67

Sinclair ARE, Mduma S, Brashares JS (2003) Patterns of predation in a diverse predator-prey system. Nature 425:288-290

Slattery M, Lesser MP (2014) Allelopathy in the tropical alga Lobophora variegata (Phaeophyceae): mechanistic basis for a phase shift on mesophotic coral reefs? J. Phycol. 50:n/a-n/a

Smith TB (2008) Temperature effects on herbivory for an Indo-Pacific parrotfish in Panam\{á\}: implications for coral-algal competition. Coral Reefs 27:397-405

Spalding HL, Copus JM, Bowen BW, Kosaki RK, Longenecker K, Montgomery AD, Padilla-gamiño JL, Parrish FA, Roth MS, Rowley SJ, Toonen RJ, Pyle RL (2019) The Hawaiian Archipelago. In: Loya Y., Puglise K.A., Bridge T.C.L. (eds) Mesophotic Coral Ecosystems. Coral Reefs of the World, vol 12. Springer, Cham.

Steneck RS, Bellwood DR, Hay ME (2017) Herbivory in the marine realm: shaping ecosystems and colliding with the Anthropocene. Curr. Biol. 27:in press 
Stoepler TM, Lill JT (2013) Direct and indirect effects of light environment generate ecological trade-offs in herbivore performance and parasitism. Ecology 94:2299-310

Tootell JS, Steele MA (2016) Distribution, behavior, and condition of herbivorous fishes on coral reefs track algal resources. Oecologia 181:13-24

Wootton JT, Power ME (1993) Productivity, consumers, and the structure of a river food chain. Proc. Natl. Acad. Sci. U. S. A. 90:1384-7

Table 1: Highest ranking DistLM models using BEST selection procedure.

\begin{tabular}{lll}
\hline AIC & R2 & Selections \\
\hline 926.53 & 0.138 & Coral, Sand, Light \\
926.93 & 0.150 & Turf Algae, Coral, Sand, Light \\
927.24 & 0.118 & Coral, Light \\
927.28 & 0.147 & Coral, Sand, Light, Piscivore \\
927.31 & 0.117 & Coral, Sand \\
\hline
\end{tabular}

\section{Figure Legends}

Figure 1: Locations of surveys sites along West Hawai'i. Starred sites indicate locations of behavioral studies.

Figure 2: Mean ( \pm SEM) abundance of a) Acanthuridae, b) Scarinae, c) Pomacanthidae, and d) other herbivorous fishes by region across survey depths $(\mathrm{m})$.

Figure 3: Mean (+/- SEM) abundance of a) mobile vs. site-attached predators, and b) piscivorous fishes within each region across survey depths $(\mathrm{m})$.

Figure 4: Mean ( \pm SEM) proportion of time a) Zebrasoma flavescensand b) Scarus psittacus displayed each behavior. 


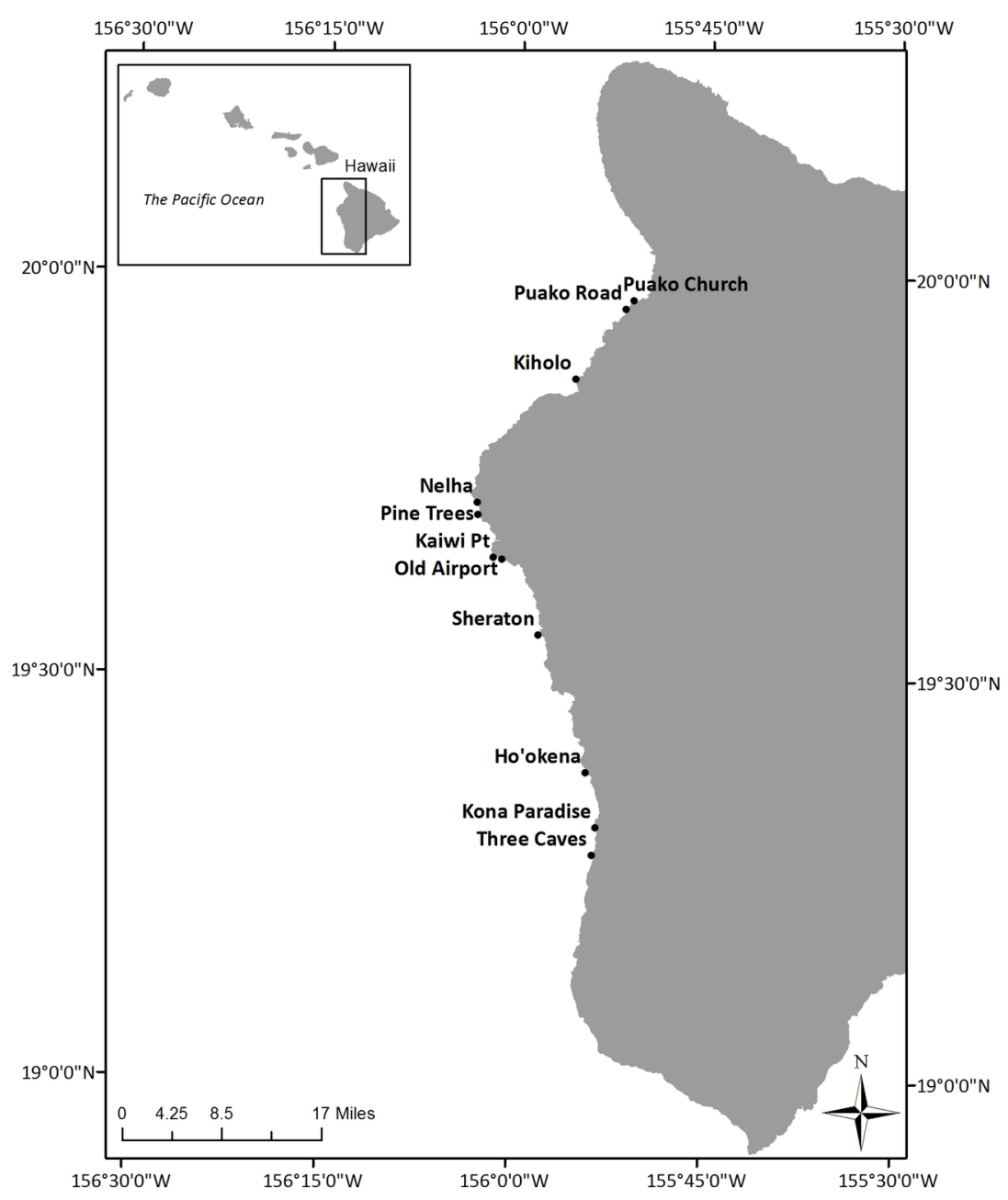

Figure 1: Locations of surveys sites along West Hawai'i. Starred sites indicate locations of behavioral studies.

\section{Hosted file}

image2.emf available at https://authorea.com/users/363312/articles/484116-non-consumptivepredator-effects-constrain-herbivorous-fish-distribution-and-abundance-at-uppermesophotic-depths-30-50-m

Figure 2: Mean ( \pm SEM) abundance of a) Acanthuridae, b) Scarinae, c) Pomacanthidae, and d) other herbivorous fishes by region across survey depths $(\mathrm{m})$.

\section{Hosted file}

image3.emf available at https://authorea.com/users/363312/articles/484116-non-consumptivepredator-effects-constrain-herbivorous-fish-distribution-and-abundance-at-uppermesophotic-depths-30-50-m 
Figure 3: Mean (+/- SEM) abundance of a) mobile vs. site-attached predators, and b) piscivorous fishes within each region across survey depths $(\mathrm{m})$.

\section{Hosted file}

image4.emf available at https://authorea.com/users/363312/articles/484116-non-consumptivepredator-effects-constrain-herbivorous-fish-distribution-and-abundance-at-uppermesophotic-depths-30-50-m

Figure 4: Mean ( \pm SEM) proportion of time a) Zebrasoma flavescensand b) Scarus psittacus displayed each behavior. 